\title{
DEPOSIÇÃO DE CALDA PULVERIZADA NA CULTURA DA SOJA PROMOVIDA PELA APLICAÇÃO AÉREA E TERRESTRE
}

\author{
JOÃO P. A. R. DA CUNHA ${ }^{1}$, ALBERTO C. FARNESE ${ }^{2}$, JUAN J. OLIVET ${ }^{3}$, \\ JUANA VILLALBA ${ }^{4}$
}

\begin{abstract}
RESUMO: Este trabalho teve como objetivo avaliar o efeito da tecnologia de aplicação aérea e terrestre de fitossanitários na deposição de calda, na cultura da soja. Avaliou-se, após a aplicação de um traçador, a deposição nas partes inferior e superior do dossel da cultura, por meio de espectrofotometria. O ensaio foi conduzido no delineamento em blocos ao acaso, com quatro repetições e oito tratamentos (formas de aplicação): 1 - Terrestre (Ponta de jato cônico vazio-TXA 8002 e $180 \mathrm{~L} \mathrm{ha}^{-1}$ ); 2 - Terrestre (Ponta de jato plano defletor duplo com indução de ar-AITTJ 11002 e $150 \mathrm{~L} \mathrm{ha}^{-1}$ ); 3 - Terrestre (Ponta de jato plano defletor com indução de ar-TTI $11002 \mathrm{e}$ $150 \mathrm{~L} \mathrm{ha}^{-1}$ ); 4 - Terrestre (Ponta de jato plano defletor duplo-TTJ60 11002 e $150 \mathrm{~L} \mathrm{ha}^{-1}$ ); 5 Terrestre (Ponta de jato plano defletor-TT 11002 e $150 \mathrm{~L} \mathrm{ha}^{-1}$ ); 6 - Aéreo (Atomizador rotativo e $40 \mathrm{~L} \mathrm{ha}^{-1}$ ); 7 - Aéreo (Atomizador rotativo e $30 \mathrm{~L} \mathrm{ha}^{-1}$ ); e 8 - Aéreo (Atomizador rotativo e $20 \mathrm{~L} \mathrm{ha}^{-1}$ ). Também foi conduzido um estudo de espectro de gotas. As aplicações terrestres com ponta de jato cônico vazio e aérea $\left(40 \mathrm{~L} \mathrm{ha}^{-1}\right)$ foram as mais eficientes em promover a penetração da calda no dossel, embora seus espectros de gotas sejam mais suscetíveis à deriva. A aplicação aérea mostrou-se viável tecnicamente, quanto à deposição de calda, em comparação aos tratamentos terrestres.
\end{abstract}

PALAVRAS-CHAVE: tecnologia de aplicação, aviação agrícola, pulverização, Glycine max.

\section{SPRAY DEPOSITION ON SOYBEAN CROP IN AERIAL AND GROUND APPLICATION}

ABSTRACT: This study aimed to evaluate the effect of aerial and ground application technology in spray deposition on soybean crop. It was evaluated the spray deposition on the bottom and the top of the plant canopy, after application of a tracer, by spectrophotometric technique. The experiment was conducted in a randomized block design with four replications and eight treatments (application technologies): 1 - Ground (Hollow cone nozzle-TXA 8002 and $180 \mathrm{~L} \mathrm{ha}^{-1}$ ) 2 - Ground (Air induction turbo twin flat fan nozzle-AITTJ 11002 and $150 \mathrm{~L} \mathrm{ha}^{-1}$ ), 3 - Ground (Air induction turbo flat fan nozzle-TTI 11002 and $150 \mathrm{~L} \mathrm{ha}^{-1}$ ), 4 - Ground (Turbo twin flat fan nozzle-TTJ60 11002 and $150 \mathrm{~L} \mathrm{ha}^{-1}$ ), 5 - Ground (Turbo flat fan nozzle-TT 11002 and $150 \mathrm{~L} \mathrm{ha}^{-1}$ ) 6 - Aerial (Rotary atomizers and $40 \mathrm{~L} \mathrm{ha}^{-1}$ ) 7 - Aerial (Rotary atomizers and $30 \mathrm{~L} \mathrm{ha}^{-1}$ ) and 8 - Aerial (Rotary atomizers and $\left.20 \mathrm{~L} \mathrm{ha}^{-1}\right)$. The droplet spectra were also evaluated. It was concluded that ground application with hollow cone nozzle and aerial with rotary atomizers $\left(40 \mathrm{~L} \mathrm{ha}^{-1}\right)$ were the most effective in promoting the droplet penetration into soybean canopy, although their droplet spectra were more susceptible to drift. The aerial application was technically feasible in spray deposition, compared to ground treatments.

KEYWORDS: application technology, agricultural aviation, spray, Glycine max.

\footnotetext{
${ }^{1}$ Eng ${ }^{\mathrm{o}}$ Agrícola, Prof. Doutor, Instituto de Ciências Agrárias, Universidade Federal de Uberlândia, Uberlândia - MG, jpcunha@iciag.ufu.br.

${ }^{2}$ Estudante do Curso de Agronomia, Instituto de Ciências Agrárias, Universidade Federal de Uberlândia, Uberlândia - MG, betimfarnese@yahoo.com.br.

${ }^{3}$ Eng $^{\mathrm{O}}$ Agrônomo, Prof. Doutor, Facultad de Agronomía, Universidad de la República, Montevideo, Uruguay, juanjoseolivet@gmail.com.

${ }^{4}$ Eng $^{\underline{a}}$ Agrônoma, Profa. Doutora, Facultad de Agronomía, Universidad de la República, Paysandu, Uruguay, juanavil@adinet.com.uy. 


\section{INTRODUÇÃO}

A soja, Glycine $\max$ (L.) Merrill, é mundialmente caracterizada como um cultivo de grande importância econômica. Trata-se de uma cultura com inúmeros desafios para uma produção com qualidade e alta produtividade, e, dentre estes, está o controle eficaz de pragas e principalmente doenças foliares fúngicas, que normalmente demandam duas ou três aplicações de fungicidas.

Com a disseminação da ferrugem asiática (Phakopsora pachyrhizi H. Sydow \& Sydow) e a ausência de cultivares resistentes para controle dessa doença, foi intensificado o uso de fitossanitários (YORINORI et al., 2005). Mais recentemente, o mofo-branco, doença causada pelo fungo Sclerotinia sclerotiorum (Lib.) de Bary, também tem ocasionado grandes problemas à cultura da soja, principalmente pela sua dificuldade de controle (CALLA et al., 2009). Da mesma forma como o rápido fechamento, com sombreamento das entrelinhas, antes do florescimento, maximiza o potencial produtivo da soja, também favorece a ocorrência de condições ideais para o desenvolvimento destas doenças. Neste sentido, o fungicida selecionado, seja de ação de contato, seja sistêmica, deve ser posicionado no alvo no momento correto e de forma adequada, para se obter um controle econômico e racional das doenças. Além disso, a ação sistêmica dos fungicidas é pouco pronunciada em soja, reforçando a importância da distribuição do produto.

De acordo com CUNHA et al. (2008), a cobertura do dossel da soja, proporcionada pela aplicação de fungicida, em geral é baixa, principalmente na parte inferior, resultando em controle ineficiente, mesmo com produtos sistêmicos. Ainda de acordo com esses autores, é necessário estudar estratégias que incrementem a deposição de gotas da pulverização de produtos fitossanitários na parte inferior do dossel.

Assim, para o sucesso da aplicação, além de se conhecer a natureza do produto, também é necessário dominar a forma adequada de aplicação, de modo a garantir que o produto alcance o alvo de forma eficiente, minimizando as perdas e reduzindo a contaminação do ambiente (CUNHA et al., 2005). Muitas vezes, parte do produto aplicado perde-se no ambiente, principalmente pela má qualidade da aplicação, seja ela terrestre, seja aérea, sendo este um dos maiores problemas da agricultura moderna a ser superado (CUNHA et al., 2006; CUNHAET AL., 2008). De pouco adiantará produzir a gota adequada, se o produto não atingir o alvo (CARVALHO, 2007).

Desse modo, a tecnologia de aplicação é uma ferramenta que pode ser usada para maximizar a produtividade quando utilizada de maneira correta. Nesse contexto, tem-se a aplicação aérea, que é uma realidade em boa parte das regiões produtoras de grãos no Brasil. Seu uso tem crescido muito, contudo pouca informação científica existe a respeito de sua eficácia, principalmente em comparação à aplicação convencional, o que causa desconfiança por parte de agricultores quanto à sua viabilidade técnica, sobretudo quanto à capacidade de penetração da calda pulverizada no dossel das culturas. Com relação ao volume de calda a ser aplicado, também existe pouca informação. Em geral, para a aplicação aérea, recomendam-se volumes entre 15 e $40 \mathrm{~L} \mathrm{ha}^{-1}$, contudo essa faixa é bastante ampla e precisa ser mais bem estudada.

Dependendo do estádio de desenvolvimento da planta, a aplicação terrestre pode ocasionar a redução do estande da lavoura, área fotossintética e, consequentemente, perdas de grãos, reduzindo significativamente a produção pelo amassamento (SILVA, 2004). No momento em que as aplicações de fungicidas proporcionam maior resposta técnica e econômica, o porte das plantas dificulta ou até impede o deslocamento das máquinas convencionais no interior das lavouras (BOLLER et al., 2008).

Desta forma, este trabalho teve como objetivo avaliar o efeito da tecnologia de aplicação aérea e terrestre, empregada para a pulverização, na deposição de calda sobre a cultura da soja.

\section{MATERIAL E MÉTODOS}

O trabalho foi realizado na Fazenda Gaia, localizada no município de Monte Alegre de Minas (Minas Gerais, Brasil), cuja latitude e longitude aproximadas são $18^{\circ} 52^{\prime}$ sul e $48^{\circ} 52^{\prime}$ oeste. A área 
pertence à Bacia do Rio Paraná, com altitude média entre 850 e $900 \mathrm{~m}$. O relevo é suave ondulado. O clima da região foi classificado como Aw, pelo Sistema de Köeppen. Apresenta inverno frio e seco e verão quente e chuvoso (entre os meses de outubro e março). A precipitação total anual é de 1.400 a $1.500 \mathrm{~mm}$. A temperatura média anual está entre 20 e $24{ }^{\circ} \mathrm{C}$, variando de $18{ }^{\circ} \mathrm{C}$, para o mês mais frio, a $25{ }^{\circ} \mathrm{C}$, para o mês mais quente. A vegetação característica da área é o cerrado. $\mathrm{O}$ solo foi classificado como Latossolo Vermelho distrófico típico, textura média.

Realizou-se a semeadura direta da cultivar de soja BRSGO Luziânia RR, de ciclo semi-precoce, com espaçamento entre fileiras de $0,5 \mathrm{~m}$ e 14 plantas por metro linear. O experimento constou de oito tratamentos e quatro repetições, sendo três tratamentos aéreos e cinco terrestres (Tabela 1). Os tratamentos 1 e 6 reproduziram as condições utilizadas na fazenda, em área comercial.

As aplicações foram feitas simulando o controle da ferrugem asiática, estando a soja em estágio R4 (vagens em formação), com cobertura total do solo. Foi utilizado um pulverizador tratorizado de arrasto e uma aeronave agrícola, conforme os tratamentos propostos.

TABELA 1. Descrição dos tratamentos. Specifications of treatments.

\begin{tabular}{cccc}
\hline Tratamento & \multicolumn{2}{c}{ Máquina para Aplicação Volume de Aplicação } & Modelo de Ponta/Atomizador \\
\hline 1 & Pulverizador terrestre & $180 \mathrm{~L} \mathrm{ha}^{-1}$ & $\begin{array}{c}\text { Jato cônico vazio (TXA 8002) } \\
\text { Jato plano defletor duplo com indução } \\
\text { de ar (AITTJ 11002) }\end{array}$ \\
& $\begin{array}{c}\text { Pulverizador terrestre } \\
3\end{array}$ & $\begin{array}{c}150 \mathrm{~L} \mathrm{ha}^{-1} \\
\text { Pulverizador terrestre }\end{array}$ & $\begin{array}{c}150 \mathrm{~L} \mathrm{ha}^{-1} \\
\text { Jato plano defletor com indução de ar } \\
\text { (TTI 11002) }\end{array}$ \\
4 & Pulverizador terrestre & $150 \mathrm{~L} \mathrm{ha}^{-1}$ & Jato plano defletor duplo (TTJ60 \\
5 & Pulverizador terrestre & $150 \mathrm{~L} \mathrm{ha}^{-1}$ & Jato plano defletor (TT 11002) \\
6 & Avião agrícola & $40 \mathrm{~L} \mathrm{ha}^{-1}$ & Micronair (AU 5000) \\
7 & Avião agrícola & $30 \mathrm{~L} \mathrm{ha}^{-1}$ & Micronair (AU 5000) \\
8 & Avião agrícola & $20 \mathrm{~L} \mathrm{ha}^{-1}$ & Micronair (AU 5000) \\
\hline
\end{tabular}

O pulverizador utilizado apresentava depósito de calda de $3.000 \mathrm{~L}, 18 \mathrm{~m}$ de barra e sistema de marcação de linha por espuma. A altura da barra de pulverização em relação à cultura foi de $0,5 \mathrm{~m}$ e a distância entre bicos de $0,4 \mathrm{~m}$. Foram avaliadas cinco pontas de pulverização, conforme descrito na Tabela 1. O volume de aplicação empregado foi de $180 \mathrm{~L} \mathrm{ha}^{-1}$, e a pressão de trabalho, de $700 \mathrm{kPa}$, para a ponta de jato cônico vazio, e $150 \mathrm{~L} \mathrm{ha}^{-1}$ e $450 \mathrm{kPa}$, para as pontas de jato plano. Em todos os tratamentos tratorizados, a velocidade de deslocamento foi de aproximadamente $8 \mathrm{~km} \mathrm{~h}^{-1}$. A aeronave utilizada, modelo Ipanema 201A, estava equipada com oito atomizadores rotativos de tela, modelo Micronair AU 5000, sistema de balizamento por DGPS e fluxômetro, e operou na velocidade de $177 \mathrm{~km} \mathrm{~h}^{-1}$ (110 milhas $\mathrm{h}^{-1}$ ) e altura de voo em relação ao dossel da cultura de $4 \mathrm{~m}$. Empregaram-se volumes de aplicação de 20; 30 e $40 \mathrm{~L} \mathrm{ha}^{-1}$. O ângulo de pás do atomizador foi regulado em $45^{\circ}$, a unidade de restrição variável foi posicionada para atender aos volumes de calda propostos e a pressão média de $241 \mathrm{kPa}$, podendo ocorrer pequenas variações em função dos ajustes automáticos do fluxômetro.

O comprimento das parcelas experimentais foi de $300 \mathrm{~m}$ e a largura útil para os tratamentos aéreos, $15 \mathrm{~m}$, e para os terrestres, $9 \mathrm{~m}$. Essas larguras foram utilizadas de acordo com a faixa de deposição da aeronave em cada condição de aplicação (ASAE, 2004) e, para a aplicação terrestre, correspondeu à metade da barra do pulverizador. Nos tratamentos aéreos, para cada parcela, o avião realizou quatro passadas para garantir a sobreposição adequada, com direção do vento lateral ao sentido de deslocamento (vento de través).

A avaliação da eficiência dos tratamentos na deposição da calda pulverizada, na cultura da soja, foi realizada utilizando-se de um traçador composto do corante alimentício Azul Brilhante 
(catalogado internacionalmente pela "Food, Drug \& Cosmetic" como FD\&C Blue n.1). O corante foi utilizado, junto à calda, na dose de $400 \mathrm{~g} \mathrm{ha}^{-1}$ (ajustando-se a quantidade de corante adicionada ao tanque em função do volume de aplicação empregado), sendo detectado por absorbância em espectrofotometria. Para tanto, foi utilizado um espectrofotômetro (fotômetro fotoelétrico, Biospectro SP22), com lâmpada de tungstênio-halogênio.

Após a pulverização, foram marcadas dez plantas ao acaso em cada parcela e, em cada planta, foram coletadas duas folhas: uma na parte central do terço superior ( $90 \mathrm{~cm}$ de altura) e outra na parte central do terço inferior da planta $(30 \mathrm{~cm}$ de altura), próximas à haste principal. As folhas foram, então, agrupadas por posição na planta e colocadas em sacos plásticos, adicionando-se 50 $\mathrm{mL}$ de água destilada. Esses sacos foram fechados, agitados por $30 \mathrm{~s}$ e acondicionados em recipientes providos de isolamento térmico e luminoso para o transporte até o Laboratório de Mecanização Agrícola da Universidade Federal de Uberlândia (Uberlândia - MG, Brasil). Posteriormente, foi feita a quantificação da coloração por absorbância em $630 \mathrm{~nm}$ (faixa de detecção do corante azul utilizado), com o uso do espectrofotômetro, conforme metodologia apresentada por PALLADINI et al. (2005). De acordo com PINTO et al. (2007), o traçador Azul Brilhante é estável por um período de $5 \mathrm{~h}$ de exposição solar. As folhas tiveram sua área medida através do programa de análise de imagens "Image Tool” (University of Texas, Texas, USA), após serem digitalizadas.

Com o uso das curvas de calibração, obtidas por meio de soluções-padrão, os dados de absorbância foram transformados em concentração $\left(\mathrm{mg} \mathrm{L}^{-1}\right)$ e, de posse da concentração inicial da calda e do volume de diluição das amostras, determinou-se a massa de corante retido no alvo. Procedeu-se, então, à divisão do depósito total pela área foliar de remoção, obtendo-se, assim, a quantidade em $\mu \mathrm{g} \mathrm{cm}^{-2}$ de folha, nas partes superior e inferior do dossel. Também foi calculada a razão entre as massas retidas nas duas posições.

Foi conduzido, além disso, um estudo do espectro de gotas pulverizadas, visando a caracterizar os tratamentos, por meio da avaliação das gotas depositadas em papéis sensíveis à água (76 x $26 \mathrm{~mm}$ ), de acordo com HALLEY et al. (2008). Antes da pulverização, foram colocados quatro papéis hidrossensíveis em cada parcela, todos suspensos em uma haste metálica imediatamente acima das plantas e mantidos na posição horizontal, voltados para cima. Posteriormente, foi feita a quantificação e a caracterização dos impactos em cada papel. Para isso, os papéis foram digitalizados por meio de um scanner (resolução espacial de 600 dpi não interpolados, com cores em 24 bits) e analisados, utilizando-se do programa computacional CIR 1.5 (Conteo y Tipificación de Impactos de Pulverización), específico para essa finalidade. Determinaram-se o diâmetro da mediana volumétrica (DMV ou $\mathrm{D}_{\mathrm{v} 0,5}$ ), o diâmetro da mediana numérica (DMN), a amplitude relativa (AR) e a percentagem do volume pulverizado composto por gotas com diâmetro inferior a $100 \mu \mathrm{m}$ (Gotas < $100 \mu \mathrm{m})$.

A amplitude relativa foi determinada, utilizando-se da seguinte eq.(1):

$$
\mathrm{AR}=\frac{\mathrm{D}_{\mathrm{v} 0,9}-\mathrm{D}_{\mathrm{v} 0,1}}{\mathrm{D}_{\mathrm{v} 0,5}}
$$

em que,

$\mathrm{D}_{\mathrm{v} 0,1}$ - diâmetro de gota tal que $10 \%$ do volume do líquido pulverizado é constituído de gotas menores que esse valor, $\mu \mathrm{m}$;

$\mathrm{D}_{\mathrm{v} 0,5}$ - diâmetro de gota tal que $50 \%$ do volume do líquido pulverizado é constituído de gotas menores que esse valor (DMV), $\mu \mathrm{m}, \mathrm{e}$

$\mathrm{D}_{\mathrm{v} 0,9}$ - diâmetro de gota tal que $90 \%$ do volume do líquido pulverizado é constituído de gotas menores que esse valor, $\mu \mathrm{m}$. 
Durante as aplicações, foram monitoradas as condições ambientais de temperatura, umidade relativa do ar e velocidade do vento: temperatura variando ente 24 e $30{ }^{\circ} \mathrm{C}$, umidade relativa entre 62 e $80 \%$ e velocidade do vento entre 3,3 e $6,2 \mathrm{~km} \mathrm{~h}^{-1}$.

Para fins de análise estatística, o estudo de deposição e espectro de gotas foi realizado segundo o delineamento em blocos ao acaso. Os dados foram submetidos à analise de variância, e as médias foram comparadas pelo teste de Tukey, a 0,05 de probabilidade. Foram aplicados os testes de Lilliefors e Bartlett para verificar a normalidade dos erros e a homogeneidade das variâncias.

\section{RESULTADOS E DISCUSSÃO}

$\mathrm{Na}$ Tabela 2, tem-se o espectro de gotas das aplicações realizadas. Este parâmetro é importante, pois dependendo do alvo e das condições de aplicação, exigem-se gotas de maior ou menor diâmetro (CÂMARA et al., 2008). Nota-se que o Teste F não foi significativo apenas para a amplitude relativa, demonstrando a não diferenciação dos tratamentos. Esta variável indica a homogeneidade do tamanho das gotas. Também o DMN, apesar do teste F significativo, não se diferenciou estatisticamente em virtude dos tratamentos.

TABELA 2. Espectro de gotas das aplicações terrestres e aéreas realizadas na cultura da soja. Droplet spectrum of aerial and ground applications on soybean crop.

\begin{tabular}{|c|c|c|c|c|}
\hline Tratamento & $\begin{array}{l}\text { DMV } \\
(\mu \mathrm{m})\end{array}$ & $\begin{array}{c}\mathrm{DMN} \\
(\mu \mathrm{m})\end{array}$ & AR & Gotas $<100 \mu \mathrm{m}(\%)$ \\
\hline 1 - Terrestre (TXA 8002, $180 \mathrm{~L} \mathrm{ha}^{-1}$ ) & $162,04 \mathrm{de}$ & $86,00 \mathrm{a}$ & 1,06 & $15,78 b c$ \\
\hline 2 - Terrestre (AITTJ 11002, $150 \mathrm{~L} \mathrm{ha}^{-1}$ ) & $329,65 b$ & $91,03 \mathrm{a}$ & 1,15 & $3,85 \mathrm{c}$ \\
\hline 3 - Terrestre (TTI 11002, $150 \mathrm{~L} \mathrm{ha}^{-1}$ ) & $510,62 a$ & $114,81 \mathrm{a}$ & 1,53 & $1,39 \mathrm{c}$ \\
\hline 4 - Terrestre (TTJ60 11002, $150 \mathrm{~L} \mathrm{ha}^{-1}$ ) & $238,29 \mathrm{~cd}$ & $112,37 \mathrm{a}$ & 1,15 & $5,64 \mathrm{c}$ \\
\hline 5 - Terrestre (TT $\left.11002,150 \mathrm{~L} \mathrm{ha}^{-1}\right)$ & $255,69 \mathrm{bc}$ & $82,10 \mathrm{a}$ & 1,30 & $8,23 \mathrm{c}$ \\
\hline 6 - Aéreo (Micronair, $40 \mathrm{~L} \mathrm{ha}^{-1}$ ) & $128,74 \mathrm{e}$ & $78,22 \mathrm{a}$ & 1,11 & $28,23 \mathrm{ab}$ \\
\hline 7 - Aéreo (Micronair, $30 \mathrm{~L} \mathrm{ha}^{-1}$ ) & $135,73 \mathrm{e}$ & $82,55 \mathrm{a}$ & 1,20 & $24,06 \mathrm{ab}$ \\
\hline 8 - Aéreo (Micronair, $20 \mathrm{~L} \mathrm{ha}^{-1}$ ) & $112,16 \mathrm{e}$ & $81,04 \mathrm{a}$ & 0,92 & $31,94 \mathrm{a}$ \\
\hline Valor de F: & $59,55 * *$ & $3,34 *$ & $2,06^{\mathrm{ns}}$ & $13,20 * *$ \\
\hline
\end{tabular}

Médias seguidas por letras distintas nas colunas diferem significativamente entre si, a 0,05 de probabilidade, pelo teste de Tukey. ${ }^{\text {ns }}$ não significativo; * significativo a 0,05 de probabilidade; ** significativo a 0,01 de probabilidade. DMV - diâmetro da mediana volumétrica; DMN - diâmetro da mediana numérica; AR - amplitude relativa; Gotas < $100 \mu \mathrm{m}$ - percentagem do volume pulverizado composto por gotas com diâmetro inferior a $100 \mu \mathrm{m}$.

Com relação ao DMV, nota-se que a indução de ar promoveu o maior tamanho de gotas na ponta TTI. Esta se diferenciou da ponta AITTJ, provavelmente em função dos dois orifícios de saída que caracterizam uma ponta de jato plano duplo e que levam a um menor tamanho de gota comparativamente a uma ponta de uma única saída. As menores gotas foram geradas pelo atomizador rotativo, que não se diferenciou da ponta de jato cônico vazio. Há que se destacar que esta ponta trabalhou a pressão mais elevada que as demais, o que, somado a sua própria característica construtiva, levou ao menor DMV entre as pontas.

A percentagem do volume pulverizado composto por gotas com diâmetro inferior a $100 \mu \mathrm{m}$ reflete o resultado encontrado para o DMV: pontas que proporcionam maior DMV produzem menores percentuais de gotas com diâmetro inferior a $100 \mu \mathrm{m}$ e, por consequência, menor risco de deriva. Nota-se que os tratamentos aéreos apresentaram o maior risco de deriva, contudo os tratamentos com 30 e $40 \mathrm{~L} \mathrm{ha}^{-1}$ não se diferenciaram da aplicação com a ponta de jato cônico vazio. As pontas de jato plano proporcionaram os menores riscos de deriva, com destaque para a ponta de jato plano defletor com indução de ar.

No tratamento terrestre com pontas de jato plano defletor com indução de ar, ocorreram os maiores valores de DMV, uma vez que estas pontas têm como característica a produção de gotas 
com ar em seu interior, maiores do que em outros modelos de pontas de mesma vazão (GULER et al., 2007). Estas gotas, ao se chocarem contra o alvo, subdividem-se, podendo melhorar a cobertura do alvo, contudo este processo ainda não está bem caracterizado pela literatura. A princípio, gotas grossas não são indicadas para aplicações que requeiram boa cobertura, contudo gotas aeradas apresentam comportamento diferenciado em relação a gotas sólidas. Dentre as vantagens deste tipo de ponta, cabe citar a diminuição da deriva e a menor influência do vento e da alta temperatura.

Na Tabela 3, tem-se o estudo de deposição do traçador no dossel da cultura da soja. Nota-se que o teste $\mathrm{F}$ foi significativo a 0,01 de probabilidade nas posições superior e inferior. Em virtude do fechamento da cultura após o florescimento, o grande problema para a aplicação do produto fitossanitário, principalmente para os fungicidas, é a chegada de produto na parte inferior. Como a maioria dos fungicidas sistêmicos não se transloca da parte superior para a inferior, é necessário que ocorra uma boa distribuição do produto, sob pena de não se conseguir eficácia adequada.

TABELA 3. Massa de traçador retida na folhagem da cultura da soja $\left(\mu \mathrm{g} \mathrm{cm}^{-2}\right.$ de folha) nas partes superior e inferior e razão entre elas, após as diferentes formas de aplicação terrestres e aéreas. Tracer mass retained in the soybean canopy $\left(\mu \mathrm{g} \mathrm{cm}^{-2}\right.$ of the leaf) on upper and lower parts and retained mass ratio between them, after aerial and ground application.

\begin{tabular}{|c|c|c|c|}
\hline Tratamento & $\begin{array}{l}\text { Massa Retida - } \\
\text { Posição Superior } \\
\left(\mu \mathrm{g} \mathrm{cm}^{-2} \text { de folha }\right)\end{array}$ & $\begin{array}{l}\text { Massa Retida - } \\
\text { Posição Inferior } \\
\left(\mu \mathrm{g} \mathrm{cm}^{-2} \text { de folha }\right)\end{array}$ & Razão \\
\hline 1 - Terrestre (TXA 8002, $180 \mathrm{~L} \mathrm{ha}^{-1}$ ) & $0,906 \mathrm{a}$ & $0,291 \mathrm{a}$ & 3,11 \\
\hline 2 - Terrestre (AITTJ $11002,150 \mathrm{~L} \mathrm{ha}^{-1}$ ) & $0,576 \mathrm{bcd}$ & $0,109 b c$ & 5,28 \\
\hline 3 - Terrestre (TTI $\left.11002,150 \mathrm{~L} \mathrm{ha}^{-1}\right)$ & $0,451 \mathrm{~cd}$ & $0,094 \mathrm{c}$ & 4,80 \\
\hline 4 - Terrestre (TTJ60 11002, $150 \mathrm{~L} \mathrm{ha}^{-1}$ ) & $0,375 d$ & $0,111 b c$ & 3,38 \\
\hline 5 - Terrestre (TT $\left.11002,150 \mathrm{~L} \mathrm{ha}^{-1}\right)$ & $0,405 \mathrm{~d}$ & $0,114 \mathrm{bc}$ & 3,55 \\
\hline 6 - Aéreo (Micronair, $40 \mathrm{~L} \mathrm{ha}^{-1}$ ) & $0,727 \mathrm{ab}$ & $0,200 \mathrm{ab}$ & 3,64 \\
\hline 7 - Aéreo (Micronair, $30 \mathrm{~L} \mathrm{ha}^{-1}$ ) & $0,627 \mathrm{bc}$ & $0,158 \mathrm{bc}$ & 3,97 \\
\hline 8 - Aéreo (Micronair, $20 \mathrm{~L} \mathrm{ha}^{-1}$ ) & $0,402 d$ & $0,112 \mathrm{bc}$ & 3,59 \\
\hline Valor de F: & $18,57 * *$ & $11,93 * *$ & $1,76^{\mathrm{ns}}$ \\
\hline
\end{tabular}

Médias seguidas por letras distintas nas colunas diferem significativamente entre si, a 0,05 de probabilidade, pelo teste de Tukey.

${ }^{\mathrm{ns}}$ não significativo; ** significativo a 0,01 de probabilidade.

Fungicidas sistêmicos, em geral, são eficazes em condições de menor cobertura em comparação aos de ação de contato, contudo deve-se levar em conta que, mesmo denominados sistêmicos, costumam apresentar apenas movimento translaminar em várias culturas, reforçando a importância da tecnologia de aplicação (BOLLER et al., 2007).

Na parte superior, houve destaque para a aplicação com a ponta de jato cônico vazio, que não se diferenciou da aplicação aérea com $40 \mathrm{~L} \mathrm{ha}^{-1}$. Entre as aplicações aéreas, os volumes de $30 \mathrm{e}$ $40 \mathrm{~L} \mathrm{ha}^{-1}$ foram semelhantes e superiores ao de $20 \mathrm{~L} \mathrm{ha}^{-1}$. Este, contudo, foi semelhante aos tratamentos terrestres com pontas de jato plano. Ressalta-se que as folhas foram coletadas no interior do terço superior e não no topo das plantas, o que auxilia a explicar as diferenças encontradas.

Na parte inferior, a tendência foi semelhante à ocorrida na parte superior. Os tratamentos mais eficientes em depositar o produto na parte inferior foram o terrestre com ponta de jato cônico e o aéreo com $40 \mathrm{~L} \mathrm{ha}^{-1}$, contudo este último não se diferenciou dos demais, com exceção do tratamento com a ponta de jato plano defletor com indução de ar.

CUNHA et al. (2006), avaliando a deposição promovida por diferentes pontas de pulverização em aplicação terrestre, constataram maior cobertura do dossel da cultura da soja quando se empregaram pontas que geram gotas com tamanho menor do que as geradas por pontas com 
indução de ar. Essas promoveram baixa cobertura do alvo em virtude da dificuldade de penetração no dossel pelas gotas grossas. NASCIMENTO et al. (2009), estudando o controle de ferrugem asiática da soja promovido por diferentes pontas de pulverização, também apontaram a eficiência de penetração de gotas finas, demonstrada pelo menor número de urédias no terço inferior da cultura após as aplicações de fungicida.

Contudo, em trabalho realizado por OZKAN et al. (2006), avaliando diferentes pontas de pulverização no controle da ferrugem asiática, encontrou-se uma superioridade das pontas de jato plano, com espectro de gotas médio, em relação às de jato plano duplo e jato cônico vazio, com espetro de gotas fino, na cobertura do dossel da soja. VILLALBA et al. (2009), estudando a deposição de calda em pulverização terrestre com várias pontas em cultivares de soja no estágio R1, também não encontraram bom desempenho, em relação à deposição de calda na parte basal, com o emprego de gotas finas em ponta de jato cônico TX6 com volume de calda de $150 \mathrm{~L} \mathrm{ha}^{-1}$. Possivelmente, a menor pressão de trabalho, associada a rajadas de vento, ajude a explicar o baixo desempenho encontrado com as gotas finas, no trabalho destes autores.

Na Tabela 3, é mostrada ainda a razão entre as massas retidas nas posições superior e inferior do dossel. Esse dado indica a desuniformidade de deposição da calda entre as duas posições analisadas. Não houve diferenças significativas entre as formas de aplicação. A deposição na parte superior foi, em média, 3,9 vezes superior à parte inferior, o que indica a desigualdade de distribuição.

VILLALBA et al. (2009), estudando a deposição em cultivares de soja no estágio R1, encontraram depósitos na região apical quase três vezes superiores aos da região basal, concordando com este trabalho. BOSCHINI et al. (2008) também mostraram que as deposições de calda ocorridas no terço inferior da cultivar de soja CD 202 foram significativamente inferiores às obtidas no terço superior, independentemente da ponta e da vazão utilizada.

As diversas pontas empregadas e a aplicação aérea não foram eficientes em promover a transposição da barreira imposta pelas folhas ao jato de pulverização. Nem mesmo a ponta de jato cônico vazio, na pressão empregada, foi capaz de reduzir essa diferença de deposição, o que demonstra que tecnologias como a assistência de ar na barra ou a energização das gotas (pulverização eletrostática) devem ser estudadas para melhorar a eficiência das aplicações. Outro fator importante de estudo para tentar reduzir o problema exposto é a população de plantas, visto que sua redução pode facilitar a penetração da calda, por meio da maior exposição da área foliar das plantas à pulverização e interceptação de radiação solar. HEIFFIG et al. (2006) trabalharam com diversas populações e espaçamentos entre plantas de soja e ressaltaram que o rápido fechamento nas entrelinhas estabelece condições de menor circulação de ar e maior umidade, o que pode favorecer a incidência de doenças, bem como prejudica a penetração e a cobertura das gotas.

\section{CONCLUSÕES}

As aplicações terrestres com ponta de jato cônico vazio $\left(180 \mathrm{~L} \mathrm{ha}^{-1}\right)$ e aérea com atomizador rotativo $\left(40 \mathrm{~L} \mathrm{ha}^{-1}\right)$ foram as mais eficientes em promover a penetração da calda no dossel da soja, embora seus espectros de gotas sejam mais suscetíveis à deriva.

A aplicação aérea mostrou-se viável tecnicamente, quanto à deposição de calda, em comparação aos tratamentos terrestres realizados.

A uniformidade de distribuição da calda, proporcionada pelas aplicações terrestres e aéreas, avaliada ao longo do dossel da soja, foi baixa. É preciso buscar estratégias que incrementem a deposição, principalmente na parte inferior da cultura. 


\section{AGRADECIMENTOS}

À Fundação de Amparo à Pesquisa do Estado de Minas Gerais (FAPEMIG-Brasil) e ao Instituto Nacional de Investigación Agropecuaria (INIA-Uruguay), pelo suporte financeiro que permitiu o desenvolvimento deste trabalho de pesquisa.

\section{REFERÊNCIAS}

ASAE. AMERICAN SOCIETY OF AGRICULTURAL ENGINEERING. Calibration and distribution pattern testing of agricultural aerial application equipment. St. Joseph, 2004. 5 p. (ASAE S 386.2)

BOLLER, W.; FORCELINI, C.A.; HOFFMANN, L.L. Tecnologia de aplicação de fungicidas parte I. Revisão Anual de Patologia de Plantas, Passo Fundo, v.15, p.243-276, 2007.

BOLLER, W.; HOFFMANN, L.L.; FORCELINI, C.A.; CASA, R.T. Tecnologia de aplicação de fungicidas - parte II. Revisão Anual de Patologia de Plantas, Passo Fundo, v.16, p.85-132, 2008.

BOSCHINI, L.; CONTIERO, R.L.; MACEDO JÚNIOR, E.K.; GUIMARÃES, V.F. Avaliação da deposição da calda de pulverização em função da vazão e do tipo de bico hidráulico na cultura da soja. Acta Scientiarum Agronomy, Maringá, v.30, n.2, p.171-175, 2008.

CALLA, B.; VUONG, T.; RADWAN, O.; HARTMAN, G.L.; CLOUGH, S.J. Gene expression profiling soybean stem tissue early response to sclerotinia sclerotiorum and in silico mapping in relation to resistance markers. The Plant Genome, Madison, v.2, n.2, p.149-166, 2009.

CUNHA, J.P.A.R.; MOURA, E.A.C.; SILVA JÚNIOR, J.L.; ZAGO, F.A.; JULIATTI, F.C. Efeito de pontas de pulverização no controle químico da ferrugem da soja. Engenharia Agrícola, Jaboticabal, v.28, n.2, p.283-291, 2008.

CUNHA, J.P.A.R.; REIS, E.F.; SANTOS, R.O. Controle químico da ferrugem asiática da soja em função de ponta de pulverização e volume de calda. Ciência Rural, Santa Maria, v.36, n.5, p.1.3601.366, 2006.

CUNHA, J.P.A.R.; TEIXEIRA, M.M.; VIEIRA, R.F. Avaliação de pontas de pulverização hidráulicas na aplicação de fungicida em feijoeiro. Ciência Rural, Santa Maria, v.35, n.5, p.1.0691.074, 2005.

CAMARA, F.T.; SANTOS, J.L.; SILVA, E.A.; FERREIRA, M. Distribuição volumétrica e espectro de gotas de bicos hidráulicos de jato plano de faixa expandida XR11003. Engenharia Agrícola, Jaboticabal, v.28, n.4, p.740-749, 2008.

CARVALHO, W.P.A. Situação atual e perspectivas da aviação agrícola no Brasil e eficácia no controle de doenças. Summa Phytopathologica, Botucatu, v.33, p.107-109, 2007. Suplemento.

HALLEY, S.S.; HOFMAN, V.; PANIGRAHI, S.; GU, H. Fungicide deposition measurement by spray volume, drop size and sprayer system in cereal grains. Applied Engineering in Agriculture, St. Joseph, v.24, n.1, p.15-21, 2008.

HEIFFIG, L.S.; CÂMARA, G.M.S.; MARQUES, L.A.; PEDROSO, D.B.; PIEDADE, S.M.S. Fechamento e índice de área foliar na cultura da soja em diferentes arranjos espaciais. Bragantia, Campinas, v.65, n.2, p.285-295, 2006.

GULER, H.; ZHU, H.; OZKAN, H.E.; DERKSEN, R.C.; YU, Y.; KRAUSE, C.R. Spray characteristics and drift reduction potential with air induction and conventional flat-flan nozzles. Transaction of the ASAE, St. Joseph, v.50, n.3, p.745-754, 2007.

NASCIMENTO, J.M.; SOUZA, C.M.A.; GAVASSONI, W.L.; BACCHI, L.M. A.; FENGLER, G.W. Controle de ferrugem asiática da soja utilizando-se de diferentes pontas de pulverização em Maracaju-MS. Ciencias Técnicas Agropecuarias, Habana, v.18, n.1, p.1-6, 2009. 
OZKAN, H.E.; ZHU, H.; DERKSEN, R.C.; GULER, H.; KRAUSE, C. Evaluation of various spraying equipment for effective application of fungicides to control asian soybean rust. Aspects of Applied Biology, Warwick, v.77, v.1, p.1-8, 2006.

PALLADINI, L.A.; RAETANO, C.G.; VELINI, E.D. Choice of tracers for the evaluation of spray deposits. Scientia Agrícola, Piracicaba, v.62, n.5, p.440-445, 2005.

PINTO, J.R.; LOECK, A.E.; SOUZA, R.T. de; LOUZADA, R.S. Estabilidade à exposição solar dos traçantes azul brilhante e amarelo tartrasina utilizados em estudos de deposição de pulverização. Revista Brasileira de Agrociência, Pelotas, v.13, n.1, p.105-107, 2007.

SILVA, M.P.L. Avaliação comparativa dos danos mecânicos às plantas por dois sistemas de aplicação de agrotóxicos líquidos. In: CONGRESSO BRASILEIRO DE ENGENHARIA AGRÍCOLA, 33., 2004, São Pedro. Anais... São Pedro: Associação Brasileira de Engenharia Agrícola, 2004. 1 CD-ROM.

VILLALBA, J.F.; DAGOBERTO, M.; COSTA, N.V.; DOMINGOS, V.D. Deposição da calda de pulverização em cultivares de soja no estádio R1. Ciência Rural, Santa Maria, v.39, n.6, p.1.7381.744, 2009.

YORINORI, J.T.; PAIVA, W.M.; FREDERICK, R.D.; COSTAMILAN, L.M.; BERTAGNOLLI, P.F.; HARTMAN, G.E.; GODOY, C.V.; NUNES JUNIOR, J. Epidemics of soybean rust (Phakopsora pachyrhizi) in Brazil and Paraguay. Plant Disease, Saint Paul, v.89, n.6, p.675-677, 2005. 